\title{
Investigation of annealing-treatment on structural and optical properties of sol-gel-derived zinc oxide thin films
}

\author{
SHENGHONG YANG*, YING LIU, YUELI ZHANG and DANG MO \\ State Key Laboratory of Optoelectronic Materials and Technologies, School of Physics and Engineering, \\ Sun Yat-Sen University, Guangzhou 510275, China
}

MS received 6 January 2009

\begin{abstract}
The transparent $\mathrm{ZnO}$ thin films were prepared on Si(100) substrates by the sol-gel method. The structural and optical properties of $\mathrm{ZnO}$ thin films, submitted to an annealing treatment in the $400-700^{\circ} \mathrm{C}$ ranges are studied by X-ray diffraction (XRD) and UV-visible spectroscopic ellipsometry (SE). XRD measurements show that all the films are crystallized in the hexagonal wurtzite phase and present a random orientation. Three prominent peaks, corresponding to the $(100)$ phase $\left(2 \theta \approx 31 \cdot 8^{\circ}\right),(002)$ phase $\left(2 \theta \approx 34.5^{\circ}\right)$, and $(110)$ phase $\left(2 \theta \approx 36 \cdot 3^{\circ}\right)$ appear on the diffractograms. The crystallite size increases with increasing annealing temperature. These modifications influence the optical properties. The optical constants and thickness of the films have been determined by analysing the SE spectra. The optical bandgap has been determined from the extinction coefficient. We found that the refractive index and the extinction coefficient increase with increasing annealing temperature. The optical bandgap energy decreases with increasing annealing temperature. These mean that the optical quality of $\mathrm{ZnO}$ films is improved by annealing.
\end{abstract}

Keywords. ZnO films; SE spectra; optical constants; optical bandgap.

\section{Introduction}

Zinc oxide has many interesting optoelectronic properties such as a wide bandgap, a large exciton binding energy of $60 \mathrm{meV}$, and high transparency in the visible region. These properties have made way for many applications ranging from light emitting diodes, UV laser, transparent field effect transistors, solar cells and other optical coating applications (Natsume and Sakata 2000; Hoffman et al 2003; Osinsky et al 2004). Due to the various attractive properties for practical applications of $\mathrm{ZnO}$ films, there has been much attention paid on the fabrication of $\mathrm{ZnO}$ films in recent years. A variety of techniques have been employed to fabricate $\mathrm{ZnO}$ thin films such as pulsed laser deposition (Kang et al 2004), rf magnetron sputtering (Lee et al 2000), chemical vapour deposition (Fay et al 2005), spray pyrolysis (Romero et al 2004) and sol-gel process (Chen et al 2005; Logothetidis et al 2008; Xuea et al 2008). Despite the crystalline quality being inferior to other vacuum deposition techniques, the sol-gel processing still offers the possibility of preparing a small as well as large-area coating of $\mathrm{ZnO}$ thin films at low cost for technological applications. Even though there are earlier reports on the optical and structural properties of $\mathrm{ZnO}$ films deposited by sol-gel (Chen et al 2005; Logothetidis et al 2008; Xuea et al 2008), there are a few systematic

*Author for correspondence (shenghongyang@163.com) studies on the effect of annealing on structural and optical properties, which are important parameters to be taken into consideration when we look for optoelectronic applications for these films. In this work, we deal with structural and optical properties of sol-gel derived $\mathrm{ZnO}$ thin films. As a consequence, the influence of annealing treatments on the structural and optical properties will also be investigated.

$\mathrm{ZnO}$ films were deposited at room temperature on $\mathrm{Si}$ (100) substrates by the sol-gel method. The key optical constants (refractive index, extinction coefficient) for the $\mathrm{ZnO}$ films were measured by spectroscopy ellipsometry (SE). SE is a non-destructive and sensitive optical technique that has been widely recognized as a reliable tool for characterizing optical properties of thin films (Azzam and Bashara 1977). In the analysis of the SE spectra, a four-phase model was employed, in which the optical properties of $\mathrm{ZnO}$ films were represented by the ForouhiBloomer (1986) model. Our main objective was to determine the optical properties of $\mathrm{ZnO}$ thin films as a function of annealing temperature.

\section{Experimental}

Figure 1 shows the flow chart of the preparation of the $\mathrm{ZnO}$ films. High-purity $\mathrm{Zn}$-acetate dihydrate ( $\mathrm{Zn}$ $\left.\left(\mathrm{CH}_{3} \mathrm{COO}\right)_{2} \cdot 2 \mathrm{H}_{2} \mathrm{O}, 99.9 \%\right)$ was used as starting materials; methylglycol $\left(\mathrm{CH}_{3} \mathrm{OCH}_{2} \mathrm{CH}_{2} \mathrm{OH}\right)$ was selected as a sol- 
vent, and diethanolamine $\left(\mathrm{C}_{4} \mathrm{H}_{11} \mathrm{NO}_{2}\right)$ was used as stabilizing agent. The concentration of zinc acetate was chosen to be $1 \mathrm{~mol} \mathrm{l}^{-1}$, and the resulting mixture was stirred for $1 \mathrm{~h}$ at $65^{\circ} \mathrm{C}$, and then $3 \mathrm{~h}$ at room temperature to yield a clear and homogeneous solution, which served as the coating solution. The coating was usually made 3 days after the solution was prepared. The precursor solution was spun-coated onto $\mathrm{Si}(100)$ wafer for different measurements.

Spin coating was performed at room temperature, with a rate of $3000 \mathrm{rpm}$ for $20 \mathrm{~s}$ and then of $5000 \mathrm{rpm}$ for another $10 \mathrm{~s}$. Si (100) substrates were ultrasonically cleaned with acetone and methanol, then etched for $1 \mathrm{~min}$ in $2 \% \mathrm{HF}$ water solution in order to remove the surface oxide, followed by de-ionized water and dried in nitrogen before spin coating. After depositing by spin coating, the films were dried at $300^{\circ} \mathrm{C}$ for $10 \mathrm{~min}$ on a hotplate to evaporate the solvent and remove organic residuals. The procedures from coating to drying were repeated many times until the desired thickness of the films was reached. The films were then inserted into a furnace and annealed in air at $400-700^{\circ} \mathrm{C}$ for $2 \mathrm{~h}$.

The film thickness was measured by profilometer (Dektak 3030). The crystal structure of the $\mathrm{ZnO}$ films was measured by using RIGAKU, D-MAX 2200 VPC $\mathrm{X}$-ray diffractometer equipped with a $\mathrm{Cu}-\mathrm{K} \alpha \quad(\lambda=$ $1.540562 \AA$ ) source. The optical properties of the films were characterized by a high precision photometric ellip-

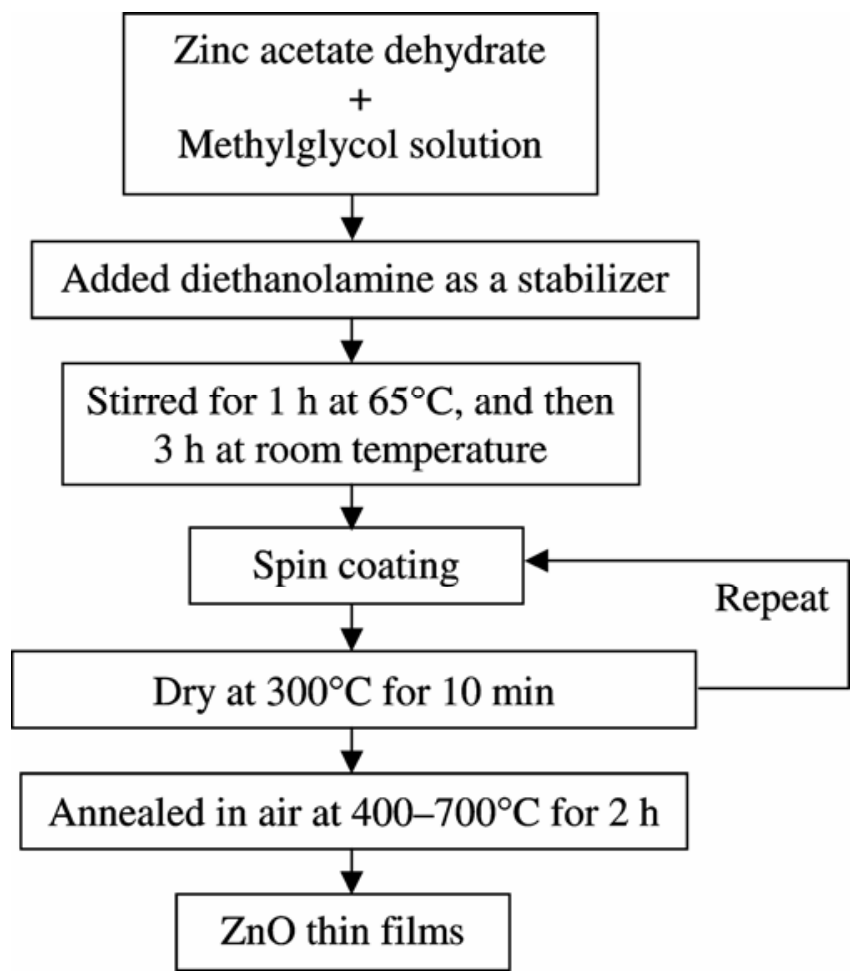

Figure 1. Flow chart for the preparation of $\mathrm{ZnO}$ thin film using sol-gel method. someter. Because the details on SE can be found in the literature (Azzam et al 1977), only a brief description is given here. In ellipsometry, the object is to measure the ratio of the complex Fresnel reflection coefficients, $\rho$, where

$$
\rho=r_{\mathrm{p}} / r_{\mathrm{s}}=\tan \psi \exp (i \Delta) .
$$

The quantity, $r_{\mathrm{p}}\left(r_{\mathrm{s}}\right)$, is the Fresnel reflection coefficients for light polarized parallel (perpendicular) to the plane of incidence, and $\psi$ and $\Delta$ are the traditional ellipsometric angles. Note that both $r_{\mathrm{p}}$ and $r_{\mathrm{s}}$ contain information on the sample of optical and structural properties. The $\tan \psi$ and $\cos \Delta$ are measured in a photometric rotating-analyser ellipsometer, by Fourier analysis of curves of the light intensity vs the azimuthal angle of the rotating analyser. The SE measurements were carried out at room temperature in the $1 \cdot 5-4.71 \mathrm{eV}$ (corresponding to $263-827 \mathrm{~nm}$ ) photo energy region at $0.03 \mathrm{eV}$ intervals, operated at an angle of incidence of $70^{\circ}$ and an azimuthal angle of the polarizer of $45^{\circ}$.

\section{Results and discussion}

Figure 2 shows X-ray diffraction patterns of $\mathrm{ZnO}$ thin films deposited on $\mathrm{Si}(100)$ substrate by spin-coating at different annealing temperatures of 400, 500, 600, and $700^{\circ} \mathrm{C}$. At $400^{\circ} \mathrm{C}$ annealing, small peaks were observed and the film shows a poor crystallinity. Films annealed at temperature $\geq 500^{\circ} \mathrm{C}$, exhibit sharp diffraction peaks characteristics of the $\mathrm{ZnO}$ wurtzite. From figure 2, (100), (002), (101), (102), (110) and (103) XRD peaks were observed, and it is concluded that all the films were polycrystalline with a hexagonal wurtzite structure and a random oriention, which generally occurs in the growth of $\mathrm{ZnO}$ thin films (Xuea et al 2008). The degree of $c$-axis orientation of the $\mathrm{ZnO}$ thin films was strongly dependent

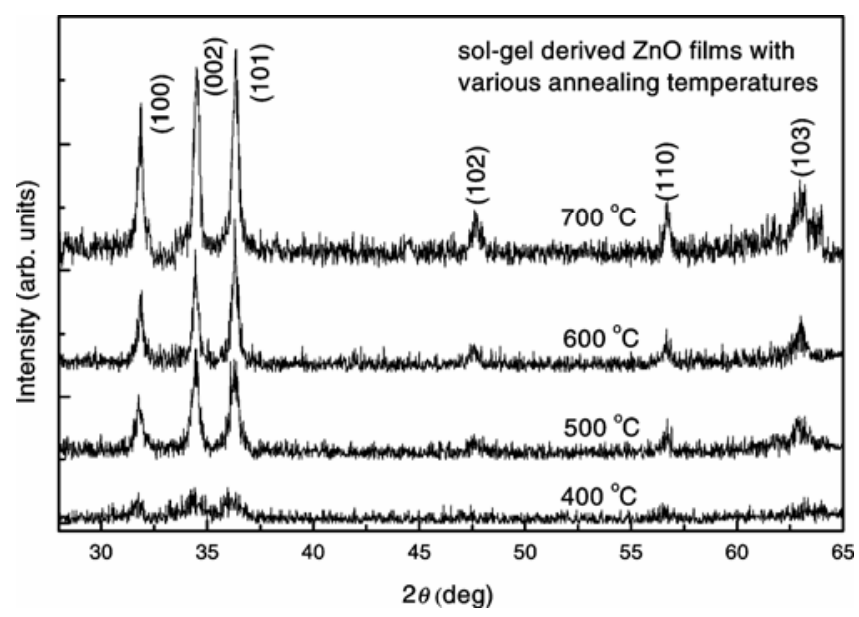

Figure 2. X-ray diffraction patterns of $\mathrm{ZnO}$ films with different annealing temperatures. 
Table 1. List of samples studied.

\begin{tabular}{lcccc}
\hline & & \multicolumn{2}{c}{ Thickness (nm) } & \\
\cline { 3 - 4 } $\begin{array}{l}\text { ZnO annealing } \\
\text { temperature }\end{array}$ & $\begin{array}{c}\text { Determined } \\
\text { by profilometer }\end{array}$ & $\begin{array}{c}\text { Determined } \\
\text { by SE }\end{array}$ & $\begin{array}{c}\text { Particle } \\
\text { sizes (nm) }\end{array}$ & $E_{\mathrm{g}}(\mathrm{eV})$ \\
\hline $400^{\circ} \mathrm{C}$ & 192 & $190 \cdot 2$ & - & $3 \cdot 405$ \\
$500^{\circ} \mathrm{C}$ & 173 & $170 \cdot 8$ & $24 \cdot 15$ & $3 \cdot 360$ \\
$600^{\circ} \mathrm{C}$ & 163 & $166 \cdot 1$ & $33 \cdot 74$ & $3 \cdot 354$ \\
$700^{\circ} \mathrm{C}$ & 155 & $154 \cdot 2$ & $34 \cdot 36$ & $3 \cdot 343$ \\
\hline
\end{tabular}

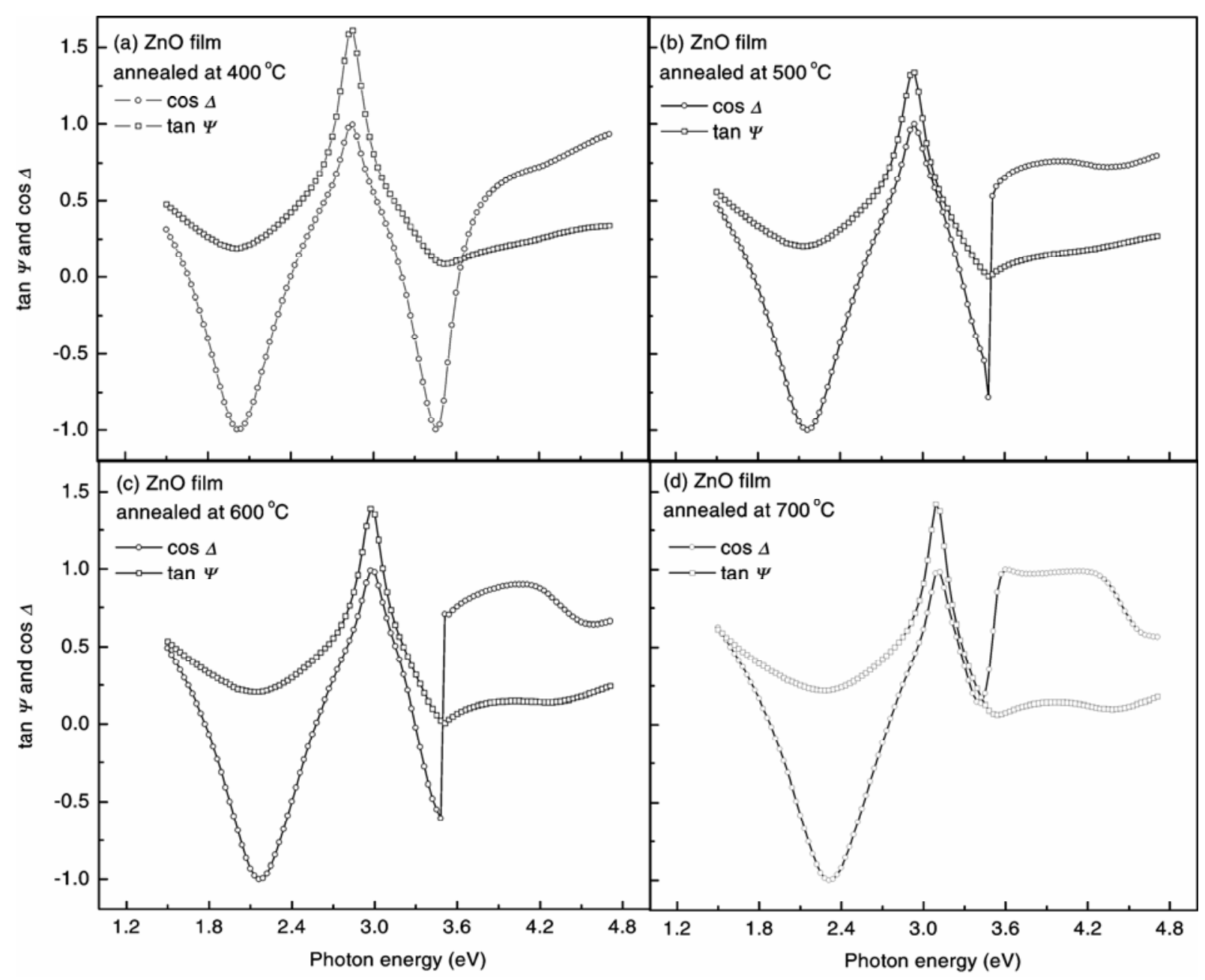

Figure 3. Experimental ellipsometric spectra of $\mathrm{ZnO}$ thin films with different annealing temperatures.

on the annealing temperature. It increases as the annealing temperature increases. The average $\mathrm{ZnO}$ thin film particle sizes were calculated using the full width at half maximum (FWHM) of (002) peak from the Scherrer's method and were presented in table 1 . The calculated values of the crystallite sizes ranged between 20 and $40 \mathrm{~nm}$. It was observed that crystallite size increased with increasing annealing temperature, which can be understood by considering the merging process induced from thermal annealing. For $\mathrm{ZnO}$ nanoparticles, there are many dangling bonds related to the zinc of oxygen defects at the grain boundaries. As a result, these defects are favourable to the merging process to form larger $\mathrm{ZnO}$ grains while increasing the annealing temperature. The $\mathrm{ZnO}$ thin film thicknesses are also presented in table 1. It was observed that increasing the annealing temperature resulted in a decrease in film thickness from $190 \mathrm{~nm}$ $\left(400^{\circ} \mathrm{C}\right.$ annealing) to $154 \mathrm{~nm}\left(700^{\circ} \mathrm{C}\right.$ annealing).

The FWHM of (002) plane of $\mathrm{ZnO}$ thin film with various annealing temperatures is also compared. As the anneal- 
ing temperature increases from $400-700^{\circ} \mathrm{C}$, the $\mathrm{FWHM}$ value exhibits a tendency to decrease, which can be attributed to the coalescences of grains at higher annealing temperature (Gupta and Mansingh 1996). As a result, it implies that the crystallinity of the $\mathrm{ZnO}$ thin films is improved at higher annealing temperatures. Other workers (Moustaghfir et al 2003; Kuo et al 2006) have also observed the improvement in crystallinity of the $\mathrm{ZnO}$ thin films with the increase of annealing temperature. These may be due to high annealing temperature providing energy to crystallites gaining enough energy to orient in proper equilibrium sites, resulting in the improvement of crystallinity and degree of orientation of the $\mathrm{ZnO}$ films.

The SE spectra for $\mathrm{ZnO}$ thin films annealed at various temperatures are shown in figures $3(\mathrm{a})-(\mathrm{d})$. The spectra can be separated into two spectral ranges. In the lower energy range, the spectra exhibit oscillations. This is only due to the interference effect of light, and this indicates that the films are transparent. The oscillating frequency depends on the thickness of the film. Generally, the thicker the film, the higher is the frequency. In the higher energy range, no interference oscillation is seen because of the occurrence of light absorption resulting from the interband transition in $\mathrm{ZnO}$ films.

The optical constants derived from the ellipsometric parameters of $\tan \psi$ and $\cos \Delta$ are analysed by a four-phase model (air/ZnO + voids $/ \mathrm{ZnO} /$ substrate). The presence of a $(\mathrm{ZnO}+$ voids) layer is due to the surface roughness, which was modeled using a Bruggeman effective medium approximation (Bruggeman et al 1933) consisting of voids and $\mathrm{ZnO}$. This feature is common for sol-gelderived oxide thin films (Raham et al 1998). The optical constants of $\mathrm{ZnO}$ were parametrized using the ForouhiBloomer models, given by (Forouhi and Bloomer 1986)

$$
\begin{aligned}
& n(E)=n_{\infty}+\frac{A\left(\begin{array}{l}
-B^{2} E+2 D B E-2 D^{2} E+ \\
2 C E+D^{2} B+B C-4 D C
\end{array}\right)}{\sqrt{4 C-B^{2}} \cdot\left(E^{2}-B E+C\right)}, \\
& k(E)=\frac{A(D-E)^{2}}{E^{2}-B E+C},
\end{aligned}
$$

where $E$ is the photon energy and the fitting parameters are $A, B, C, D$ and $n_{\infty}$. The optical constants of the substrate, $\operatorname{Si}(100)$, were taken from the work of Jellison (1992). With the help of simulated annealing optimization (Kirkpatrick et al 1983), the fitting parameters as well as the film thicknesses were determined by fitting the ellipsometric spectra. Figure 4 shows a fit for $\mathrm{ZnO}$ thin film annealed at a temperature of $700^{\circ} \mathrm{C}$.

Clearly, the fit shown in figure 4 is a good fit. The thicknesses of $\mathrm{ZnO}$ films obtained by SE closely match with those obtained by profilometer (as shown in table 1). Therefore, it is verified that our model adequately describes the measured data. Figure 5 shows the refrac- tive index $(n)$ and extinction coefficient $(k)$ obtained from the fitted parameters for $\mathrm{ZnO}$ thin films annealed at various temperatures. From figure 5, we find that the optical constants spectra of all $\mathrm{ZnO}$ films show a high refractive index $(n=1.8 \sim 2.3)$ in the $\mathrm{UV}$-visible region as well as the fundamental absorption edge in the near ultraviolet region. The refractive index first increased and then decreased as the photon energy increased from 1.5 to $4.7 \mathrm{eV}$. The extinction coefficient of the films increases as photon energy increases, consistent with KramersKronig relations. The extinction coefficients are very small at lower photon energy, where the films are nearly transparent. Our refractive index is smaller than the average value of $\mathrm{ZnO}$ bulk (refractive index $\sim 2$ ) in the visible wavelength range. This slight variation might be attributed to the porous nature of the sol-gel derived thin films. On the other hand, we also find different values of the refractive index and extinction coefficient due to the different annealing temperatures. The refractive index of the $\mathrm{ZnO}$ films increases with increasing annealing temperature. This conforms to the results already reported by Moustaghfir et al (2003). A higher annealing temperature enhances the formation of larger and more closely packed crystals. The increase of the refractive index with increasing annealing temperature can be partly attributed to improvement in film quality with the reduction in porosity in the $\mathrm{ZnO}$ film with annealing.

From the spectral relationship between extinction coefficient and photon energy (as shown in figure 5), the extinction coefficient of $\mathrm{ZnO}$ thin films can be divided into three regions: Region I having the low-energy regions $(E=1.5 \sim 2.7 \mathrm{eV}$, below the fundamental bandgap energy, $\left.E_{\mathrm{g}}\right)$; regions II and III the high-energy regions $\left(E=2.7 \sim 3.5\right.$ and $3.5 \sim 4.7 \mathrm{eV}$, above $\left.E_{\mathrm{g}}\right)$. No obvious absorption is found below the fundamental bandgap

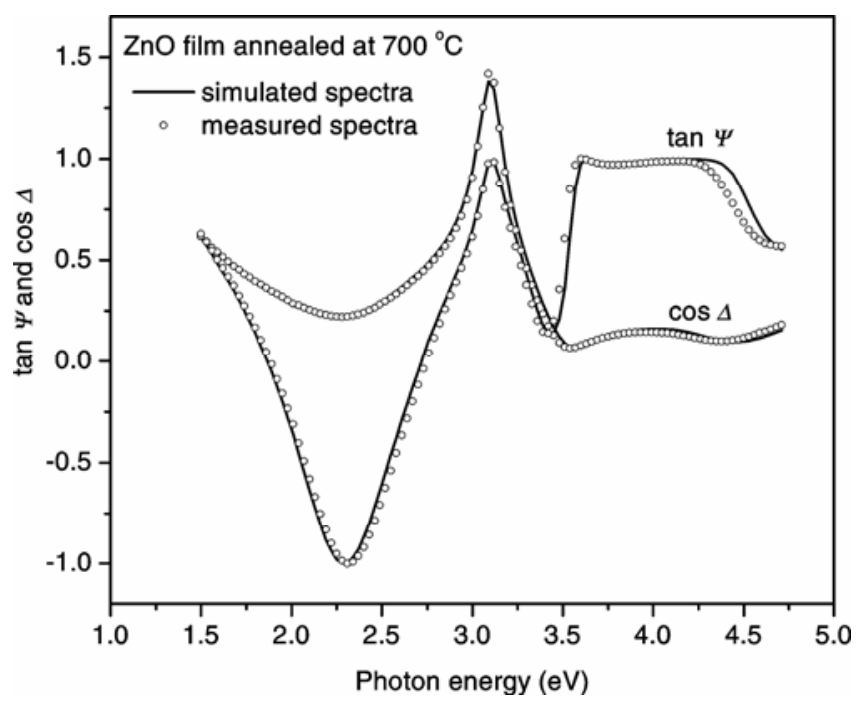

Figure 4. Experimental spectra (cycle) and calculated spectra (solid line) of $\mathrm{ZnO}$ thin films annealed at $700^{\circ} \mathrm{C}$. 
energy, $E_{\mathrm{g}}$, so the extinction coefficient is zero except when the photon energy increased close to the bandgap energy. The dispersion in regions II and III are due to the transition from the valence band to the conduction band, or a transition from a band to an impurity level. It is interesting that the extinction coefficient increases as the annealing temperature also increases in regions II and III. The values of the extinction coefficient, as we know, result from the absorption and grain scattering when the photon wavelength is equivalent to the grain size in the high-energy region. The possibility of scattering of the grains increases as the annealing temperature increases, which can also be attributed to the increase of grain size and surface density of the films. The extinction coefficient near the fundamental bandgap energy is not zero because of the noise, and the results demonstrated that some other absorption is present in addition to the fundamental transition.

The optical bandgap energy, $E_{\mathrm{g}}$, of $\mathrm{ZnO}$ films annealed at various temperatures were calculated by considering a direct allowed electronic transition between the highest occupied state of the valence band and the lowest

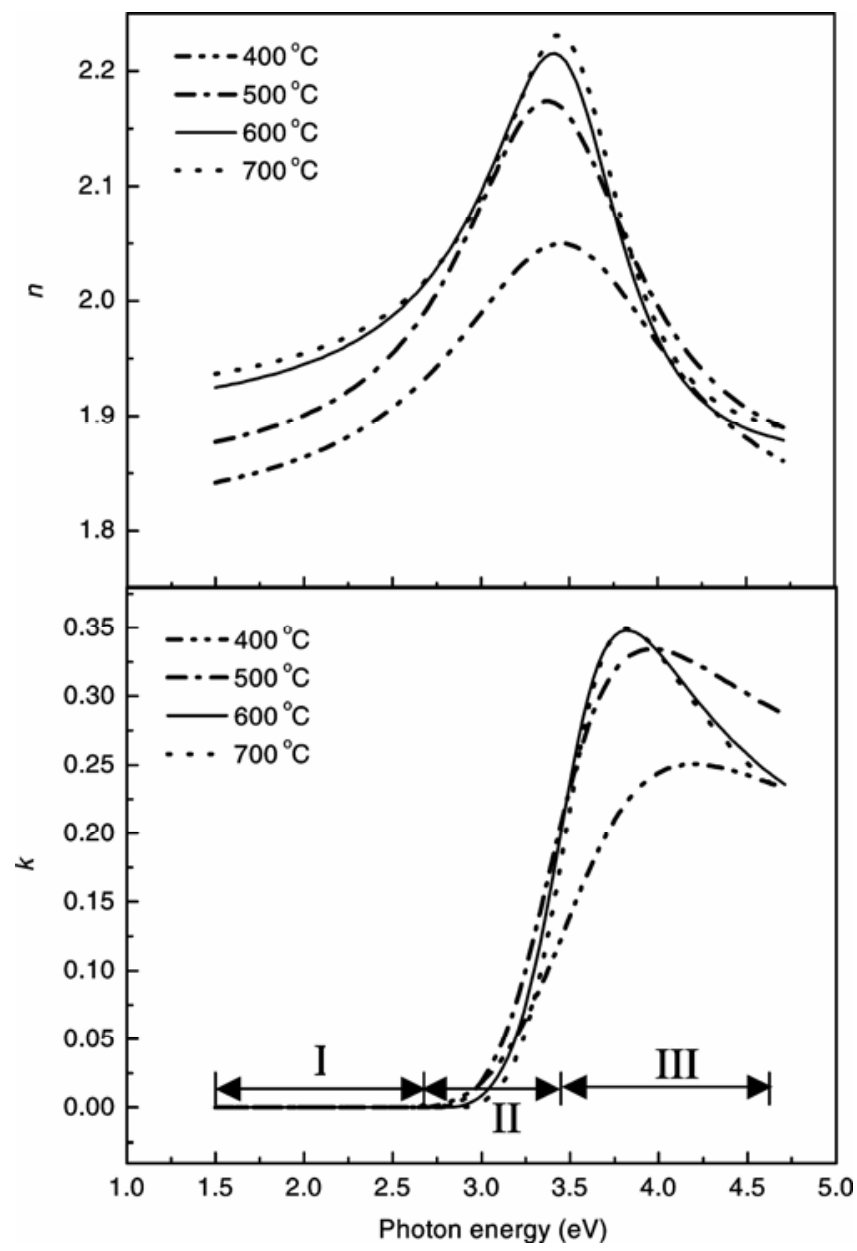

Figure 5. Optical constants ( $n$ and $k$ ) of $\mathrm{ZnO}$ thin films with different annealing temperatures. unoccupied state of the conduction band when a photon of energy, $h v$, falls on the material. In this case, the absorption coefficient, $\alpha$, is related to the optical bandgap energy, $E_{\mathrm{g}}$, as (Tauc 1974)

$$
(\alpha h v)^{2}=\text { constant } \cdot\left(h v-E_{\mathrm{g}}\right),
$$

where

$$
\alpha=4 \pi k / \lambda,
$$

the $E_{\mathrm{g}}$ values are therefore determined by extrapolating the linear portion of the plot relating $(\alpha h v)^{2}$ vs $h v$ to $(\alpha h v)^{2}=0$. As an example, figure 6 shows the optical bandgap energy for $\mathrm{ZnO}$ thin film annealed at a temperature of $700^{\circ} \mathrm{C}, E_{\mathrm{g}}=3.343 \mathrm{eV}$.

Figure 7 shows the variation of $E_{\mathrm{g}}$ with annealing temperature. The $E_{\mathrm{g}}$ value is found to decrease from 3.405-

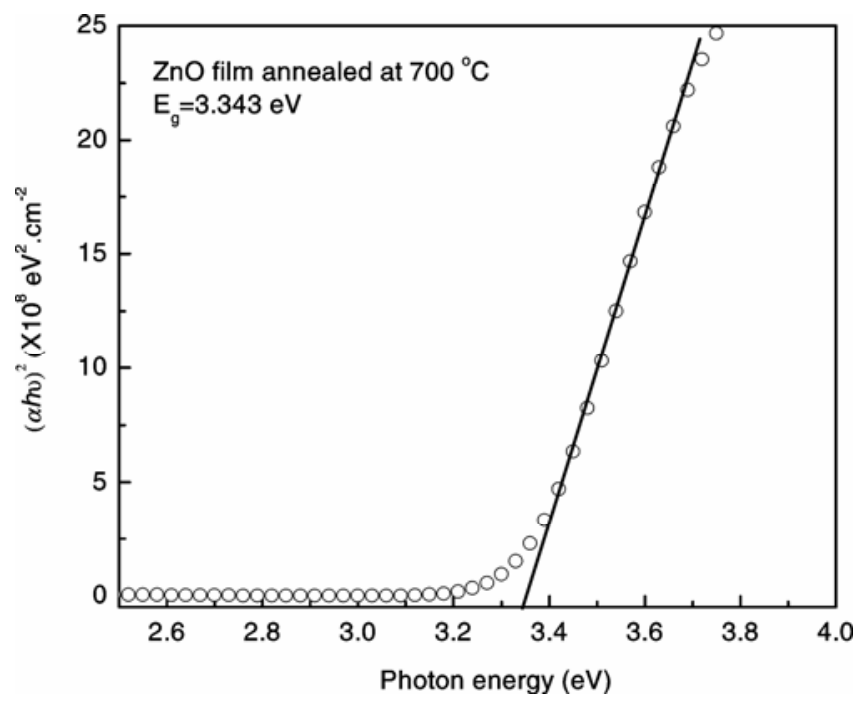

Figure 6. Plot of $(\alpha h v)^{2}$ versus $h v$ for $\mathrm{ZnO}$ thin films annealed at $700^{\circ} \mathrm{C}$, the optical bandgap energy, $E_{\mathrm{g}}$, is deduced from extrapolation of the straight line to $(\alpha h v)^{2}=0$.

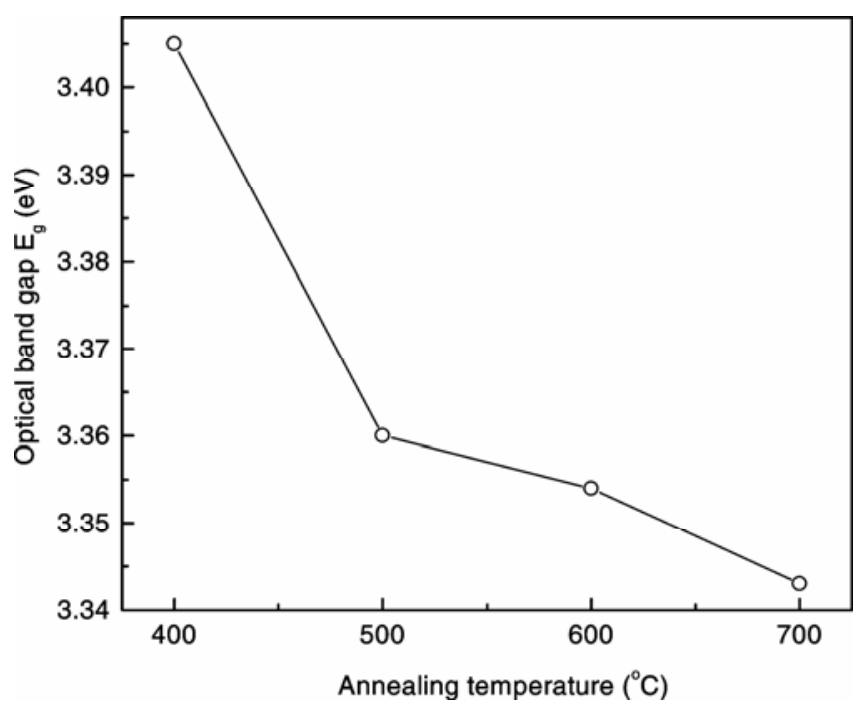

Figure 7. Optical bandgap energies of $\mathrm{ZnO}$ films as a function of annealing temperature. 
$3.343 \mathrm{eV}$ with increasing annealing temperature from $400-700^{\circ} \mathrm{C}$. The decrease in $E_{\mathrm{g}}$ indicates an improvement of the quality of the film due to the annealing out of the structural defects. This is in agreement with the experimental results of XRD analysis. According to XRD results, the mean grain size increased with increased annealing temperature. As grain size increased, the grain boundary density of a film decreased, subsequently, the scattering of carriers at grain boundaries decreased (Lee et al 2003). A continuous increase of optical constants and also a shift in absorption edge to a higher wavelength with increasing annealing temperature may be attributed to the improvement in the crystalline quality of the films along with reduction in porosity.

The decrease in optical bandgap energy is generally observed in the annealed direct-transition-type semiconductor films. Hong et al (2005) observed an optical bandgap shift of $\mathrm{ZnO}$ thin films from $3 \cdot 31-3 \cdot 26 \mathrm{eV}$ after annealing, and attributed this shift to the increase of the $\mathrm{ZnO}$ grain size. Chaparro et al (2000) ascribed this 'red shift' in the energy gap, $E_{\mathrm{g}}$, to an increase in crystallite size for the annealed ZnSe films. Bao and Yao (2001) also reported a decrease in $E_{\mathrm{g}}$ with increasing annealing temperature for $\mathrm{SrTiO}_{3}$ thin films, and suggested that a shift of the energy gap was mainly due to both the quantum-size effect and the existence of an amorphous phase in thin films. In our case, the mean crystallite size increases from 20 to $40 \mathrm{~nm}$ after annealing from 400 $700^{\circ} \mathrm{C}$. Moreover, it is understood that the amorphous phase is reduced with increasing annealing temperature, since more energy is supplied for crystallite growth, thus resulting in an improvement in crystallinity of the $\mathrm{ZnO}$ films. Therefore, it is believed that both the increase in crystallite size and the reduction in amorphous phase amount are responsible for the bandgap decreasing in annealed $\mathrm{ZnO}$ films. The change of refractive index, $n$, extinction coefficient, $k$, and optical bandgap energy, $E_{\mathrm{g}}$, reveals the impact on optical properties of thermal treatment.

\section{Conclusions}

The effect of post-annealing treatment on structural and optical properties has been critically examined in sol-gel derived $\mathrm{ZnO}$ films on $\mathrm{Si}(100)$ by XRD and SE in the UVvisible region. XRD spectra and refractive index of the films reveal that the crystalline nature of the films has significantly improved with annealing. The optical constants and optical bandgap energy of $\mathrm{ZnO}$ films were dependent on the annealing temperature. The thickness values obtained from SE measurement compare well with the surface profilometer data. The refractive index for $\mathrm{ZnO}$ films increases as the annealing temperature is increased. The optical bandgap energies have been found to decrease from 3.405 to $3.343 \mathrm{eV}$ as annealing temperature is increased from $400-700^{\circ} \mathrm{C}$. These optical property modifications can be attributed to structural modifications with different annealing temperatures.

\section{Acknowledgements}

The authors would like to gratefully appreciate the financial support from the Science and Technology Planning Project of Guangdong Province of China (Grant No. 2008B010600041) and the Natural Science Foundation of Guangdong Province of China (Grant No. $8151027501000068)$.

\section{References}

Azzam R M A and Bashara N M 1977 Ellipsometry and polarized light (Amsterdam: North-Holland) p. 89

Bao D and Yao X 2001 Appl. Phys. Lett. 793767

Bruggeman D A G 1933 Ann. Phys. Leipzig 24636

Chaparro A M, Martinez M A, Guillen C, Bayon R, Gutierrez M T and Herrero J 2000 Thin Solid Films 361177

Chen S Q, Zhang J and Feng X 2005 Appl. Surf. Sci. 241384

Fay S, Kroll U and Bucher C 2005 Sol. Energy Mater. Sol. Cells 86385

Forouhi A R and Bloomer I 1986 Phys. Rev. B34 7018

Gupta V and Mansingh A 1996 J. Appl. Phys. 801063

Hoffman R L, Norris B J and Wager J F 2003 Appl. Phys. Lett. 82733

Hong R, Huang J, He H, Fan Z and Shao J 2005 Appl. Surf. Sci. 242346

Jellison Jr. G E 1992 Opt. Mater. 141

Kang H S, Kang J S, Kim J W and Lee S Y 2004 J. Appl. Phys. 951246

Kirkpatrick S, Gelatt C D and Vecchi M P 1983 Science 220 671

Kuo S Y, Chen W C and Cheng C P 2006 Superlattices and Microstr. 39162

Lee J C, Kang K H and Kim S K 2000 Sol. Energy Mater. Sol. Cells 64185

Lee J H, Ko K H and Park B O 2003 J. Cryst. Growth 247119

Logothetidis S, Laskarakis A, Kassavetis S, Lousinian S, Gravalidis C and Kiriakidis G 2008 Thin Solid Films 516 1345

Moustaghfir A, Tomasella E, Ben Amor S, Jacquet M, Cellier J and Sauvage T 2003 Surf. Coat. Technol. 174/175 193

Natsume Y and Sakata H 2000 Thin Solid Films 37230

Osinsky A, Dong J W, Kauser M Z, Hertog B, Dabiran A M and Chow P P 2004 Appl. Phys. Lett. 854272

Raham M M, Yu G L, Krishna K M, Soga T, Wantanable J J, Jimbo T and Umeno M 1998 Appl. Opt. 37691

Romero R, Lopez M C and Leinen D 2004 Mater. Sci. Eng. B110 87

Tauc J C 1974 Amorphous and liquid semiconductor (New York: Plenum Press) p. 159

Xuea S W, Zu X T, Zhouc W L, Denga H X, Xiang X, Zhang L and Dengd H 2008 J. Alloys Compds. 44821 